Conclusions Head and brain injuries due to WRV non-vehicle injury could be an important contributor to considerable health care costs and long-term disabilities for young Queenslanders.

Learning Outcomes The findings support a revision of Queensland legislation currently not requiring WRV helmet use in the traffic environment.

\section{P5.002 HELMET USE IN POLAND: NATIONWIDE STUDY FINDINGS AND IMPLICATIONS FOR ROAD SAFETY}

Dagmara Jankowska-Karpa*, Justyna Wacowska-Slezak, Aneta Wnuk. Motor Transport Institute, Warsaw, Poland

\subsection{6/injuryprev-2021-safety.222}

Background Poland belongs to countries with one of the highest numbers of traffic victims in the European Union. Vulnerable road users are at highest risk of being injured, among them cyclists, moped riders and motorcyclists. All three groups constitute over $20 \%$ of road fatalities in Poland.

Methods In Poland studies on helmet use among cyclists, moped riders and motorcyclists have been carried out since 2013. An external observation method is used on different road categories with specially developed mobile application. In the most recent study total data on 997 motorcyclists, 812 moped riders and 4512 cyclists were analysed.

Results The helmets were used by $99 \%$ of motorcyclists (100\% riders, 99\% passengers), 99\% of moped riders (99\% riders, $94 \%$ passengers) and only $14 \%$ of cyclists (13\% riders, 94\% passengers - mainly children). The distribution of wearing helmets among cyclists was as follows: children and youth $<17$ years $(26 \%$ wearing rate), $18-24$ years (14\%), 25-60 years (13\%), >60 years (9\%); men (17\%), women $(7 \%)$.

Conclusion The results of the conducted study indicate that in comparison to previous year, the percentage of motorcyclists who wear helmets remains on the same high level, among moped riders $3 \%$ increase in the helmet wearing rate, among cyclists $2 \%$ increase. Wearing helmets by cyclist is not mandatory by law in Poland, opposed to motorcyclists and moped riders.

Learning Outcomes Road safety improvement measures, including educational and preventive initiatives, should be addressed to all age groups of cyclists, especially to older ones as they use helmets least frequently

\section{P5.003 BEHAVIOUR OF YOUNG ROAD USERS IN CONTEXT OF SCHOOL ROAD SAFETY EDUCATION}

Aneta Wnuk*. Motor Transport Institute, Warsaw, Poland

\subsection{6/injuryprev-2021-safety.223}

Background In Poland road safety education RSE is included in school curriculum. In 2018-2019 in Masovia province an observation study of students in the vicinity of primary schools was conducted, where children feel safe and comfortable.

Methods The study was carried out in 14 locations with different engineering solutions. The study was conducted in the morning. A dedicated app was used. Six types of children's behaviour were analysed: walking/riding along the road, crossing/riding across the road, using public/private transport. The data included many other variables and was analysed using a statistical description of the occurrence of frequencies. The basis for the percentage was not children but observations of their behaviour, in total 3380 children's behaviours were analysed.

Results The main issues that should be considered in RSE in Poland as indicated by the study include: as a pedestrian not looking around (62\%) and not stopping (51\%) before crossing the road, talking to others when crossing (20\%); as a cyclist - riding a bike on zebra (54\%), not signalling manoeuvres (98\%), not wearing helmets (89\%); as a passenger - getting off directly onto the street $(13 \%)$ or obstacle (20\%).

Conclusion RSE is a multi-disciplinary issue. The presented results show that we should think more about the way of implementing RSE and search for new solutions because the current ones are not effective enough.

Learning Outcomes A success of RSE depends on the cooperation of many communities (parents, schools, police etc.), equal approach to this issue and combination of actions.

\section{P5.004 SWEATING ON YOUR COMMUTE - ACTIVE TRANSPORT IN THE TROPICS: A SYNOPSIS}

1,2,3 Jemma C King * ${ }^{1,2,3}$ Richard C Franklin, ${ }^{1,3}$ Julie C Parison, ${ }^{3,4}$ Yetta Gurtner. ${ }^{1}$ College of Public Health, Medical and Veterinary Sciences, James Cook University, Townsville, Australia; ${ }^{2}$ WSO Collaborating Center for Injury Prevention and Safety Promotion James Cook University, Townsville, Australia; ${ }^{3}$ Active Transport in the Tropics Network, Townsville, Australia; ${ }^{4}$ College of Science and Engineering, James Cook University, Townsville, Australia

10.1136/injuryprev-2021-safety.224

It is not often that you get public health academics, urban planners, exercise scientists, health psychologists, educators, sociologists, transport authorities, bicycle-user group members, local council workers and concerned citizens in a room focused on a single topic. Yet the Active Transport in the Tropics Network (ATTN) has succeeded in bringing this diverse group together to focus on improving active travel. ATTN is an interdisciplinary, cross organizational network who meet at the intersection of practical discussion, research and advocacy. The aspirational goal of the network is 'to make Townsville the safest, most active, eco-friendly transport city in Australia and the tropics by 2030'. A driving factor for this goal was an acknowledgement of Townsville resident's rising weight, the abundance of sunny days and flat topography.

The network's profile and agenda has been bolstered by delivering, contributing to and representation at community consultation and public events. The network will soon release a position statement which drawing upon this foundational work, will outline: the benefits of active transport for healthy living, the importance of promoting the safety of active transport users, the need to stimulate wider community engagement and to advocate for spaces and infrastructure that are conducive for active transport. Some of the key concerns pertaining to reaching these objectives from a tropical and regional perspective include infrastructure availability and connectivity, inclusivity, social acceptability and climatic barriers (dry tropics). For active transport adoption to occur, safety needs to be prioritised; as without this, attempts to encourage individual activation is moot. 